\title{
The dispersal of staphylococci in hospital wards
}

\author{
W. C. NOBLE 1 \\ From the Air Hygiene Laboratory, Central Public Health Laboratory, Colindale, London
}

SYNOPSIS The air of three hospital wards was examined frequently for staphylococci for a period of nearly four years using slit samplers. 'Broadcasts' of staphylococci into the air were observed with the air count rising well above the mean of 0.2 staphylococcal particle per cubic foot and these broadcasts often appeared to be due to single patients.

Eight of the 3,675 patients admitted to the wards possessed an ability to disperse staphylococci into the air of the wards which was markedly greater than normal.

The actual dispersal about the ward appeared to be mediated by the bedclothes, for, when these were disturbed, large numbers of staphylococci were disseminated into the air.

During investigations of post-operative staphylococcal sepsis in surgical wards at St. Bartholomew's Hospital, London, the air of the wards was frequently examined for staphylococci. Shooter, Smith, Griffiths, Brown, Williams, Rippon, and Jevons (1958) observed 'broadcasts' of staphylococci into the air from time to time and some of these broadcasts appeared to be associated with particular patients. The study was continued and the more extensive records now available have been analysed in an attempt to discover more about the spread of staphylococci by such patients.

\section{METHODS}

The study was carried out in three male surgical wards (A, B, C). The work of the units was general surgery, although a proportion of specialized work was carried out in each ward. Wards A and C used wool blankets throughout but ward B used cellular cotton blankets for much of the investigation. Patients harbouring staphylococci resistant to penicillin and tetracycline were nursed in isolation in wards A and B but not in ward C (Williams, Noble, Jevons, Lidwell, Shooter, White, Thom, and Taylor, 1962).

The wards, which measure $56 \mathrm{ft}$. by $43 \mathrm{ft}$., have a volume of about $30,000 \mathrm{cu}$. $\mathrm{ft}$. Each has 22 beds, spaced about $6 \mathrm{ft}$. $(1 \cdot 8 \mathrm{~m}$.) apart, with three more beds in two side wards. There are cotton curtains, suspended from rails $7 \mathrm{ft}$. $(2 \cdot 1 \mathrm{~m}$.) from the floor, which can be pulled out to surround each bed. During the course of the study one of the wards, B, had four single-bed cubicles built in the body of the ward.

'Present address: The Wright-Fleming Institute of Microbiology, St. Mary's Hospital Medical School, Paddington, London, W.2.

Received for publication 16 May 1962.
A total of 3,675 patients was seen during this study. They had nasal swabs taken on admission to the wards and thereafter at weekly intervals. No systematic attempt was made to examine other possible carrier sites for staphylococci.

During the four years of the survey, the air of the wards was examined on three days each week, usually Monday, Wednesday, and Friday, using a slit sampler running for two consecutive hours. During the first year the total volume sampled daily was $48 \mathrm{cu}$. ft.; later it was $216 \mathrm{cu}$. $\mathrm{ft}$. For observing the effect of such procedures as bedmaking and wound dressing, a slit sampler drawing 6.3 or $12.6 \mathrm{cu}$. $\mathrm{ft}$. per minute was used so that adequate volumes could be sampled in short periods.

The colony count obtained using the slit sampler gives a measure of the number of airborne particles carrying staphylococci and in accordance with general usage the counts are given here as colonies per cubic foot of air sampled. For the routine ward samples the counts are given as the average for the two-hour sampling period.

The bedding was examined qualitatively for staphylococci using the sweep plate technique (Williams, Blowers, Garrod, and Shooter, 1960). For quantitative estimation of staphylococcal contamination a cellular cotton blanket was held, 7 sq. in. at a time, clamped over the mouth of a tube through which air was drawn $N$ directly into a slit sampler. The blanket was covered with a filter paper and gently percussed, the organisms thus released being collected on agar plates exposed for suc- $N$ cessive one-minute periods in the slit sampler. Experience $\sigma$ showed that about half the recoverable staphylococci appeared on the first six plates exposed, and so the total count of recoverable staphylococcal particles has been estimated by doubling the count on six successive plates.

One colony from each positive nasal culture and two colonies from each bed sweep were phage-typed. As

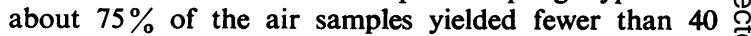
colonies of staphylococci from the $216 \mathrm{cu}$. ft. sample (less than $0 \cdot 2$ colony per cu. ft.), staphylococci from the air 
were typed as a routine only when the count rose above this level. However, up to 12 colonies from each air sample were preserved whether or not typing was indicated on the basis of the count observed. When more than two-thirds of the staphylococci recovered from the air were of the same phage type, that type was referred to as being predominant in the air.

The medium used throughout this study was Oxoid blood agar base containing $5 \%$ horse serum and $0.01 \%$ phenolphthalein-phosphate (Barber and Kuper, 1951). Phosphatase-positive colonies were tested for coagulase and were phage-typed at the Staphylococcus Reference Laboratory, Colindale. Throughout this paper the word staphylococcus is used to mean the coagulase-positive Staphylococcus aureus.

\section{RESULTS}

ROUTINE COUNTS OF AIRBORNE BACTERIA Although the total airborne flora and the number of staphylococci recovered varied from day to day, the average was remarkably similar for the three wards (Table I). During the 732 ward days of observation there were 177 days when the count of staphylococcal particles in the air was greater than 0.2 per cu. ft. (Fig. 1). On 21 days the count was greater than 1.0 per cu. $\mathrm{ft}$. and on four days greater than $2 \cdot 0$. The highest count recorded for a two-hour period was 3.4 staphylococcal particles per cubic foot.

An analysis of variance was carried out on the air

TABLE I

MEAN NUMBER OF BACTERIA IN AIR SAMPLES FROM THE THREE WARDS

\begin{tabular}{|c|c|c|c|}
\hline \multirow[t]{2}{*}{ Ward } & \multicolumn{2}{|c|}{ Colonies per Cubic Foot } & \multirow{2}{*}{$\begin{array}{l}\text { Number of } \\
\text { of Sampling }\end{array}$} \\
\hline & Total Bacterial Flora & Staphylococci & \\
\hline $\begin{array}{l}\mathbf{A} \\
\mathbf{B} \\
\mathbf{C}\end{array}$ & $\begin{array}{l}27 \cdot 0 \\
26 \cdot 4 \\
32 \cdot 7\end{array}$ & $\begin{array}{l}0.22 \\
0.18 \\
0.18\end{array}$ & $\begin{array}{l}114 \\
317 \\
321\end{array}$ \\
\hline
\end{tabular}

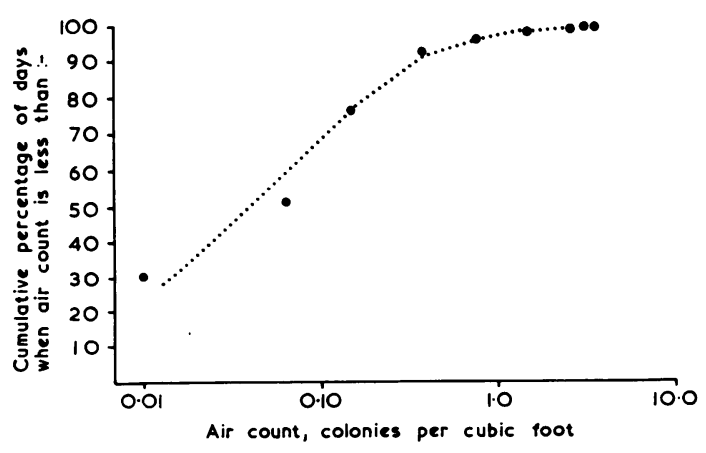

FIG. 1. Counts of airborne staphylococci. On $3 \%$ of the days no staphylococci were recovered from the air (count less than 0.01 particle per cubic foot ). counts of ward $\mathrm{C}$ over a period of 83 weeks with two samples on each of the three days each week. The variance between days and that between weeks was significant at the 0.001 level. (Variance ratio, between days $F=8.7, n_{1}=2, n_{2}=413$; variance ratio, between weeks $F=4 \cdot 1, n_{1}=82, n_{2}=413$.) Variance between the two counts on one day was not significant.

RELATION OF AIRBORNE BACTERIAL COUNTS TO CARRIERS On 162 of the 177 days when the count of airborne staphylococci was greater than 0.2 per $\mathrm{cu}$. ft., there was one type of staphylococcus predominant in the air. The phage types of the staphylococci recovered from the air were compared with those isolated from the noses or wounds of the patients at the previous weekly swabbing. For 64 of the 162 days, only one patient was found to carry the strain predominant in the air. Thirty-eight patients contributed to these 64 days; 16 patients were associated with high air counts on two or more days and eight patients were associated with high air counts throughout much of their hospital stay. These eight patients are referred to for convenience as 'dispersers'.

On a further 45 of the 162 days, one of the 38 patients referred to above and one or more other carriers were present and on 47 days several carriers were present, but it was not possible to attribute the spread of the staphylococci to any one of them. On only six of the days when the count in the air was greater than $\mathbf{0 . 2}$ particle per cu. $\mathrm{ft}$. was no carrier known to be present.

CHARACTERISTICS OF DISPERSERS Some of the characteristics of the eight dispersers observed are given in Figure 2. Six of these patients were active dispersers on admission to the wards and two became dispersers of the staphylococci that they acquired in hospital. Dispersal of the staphylococci acquired by patient $\mathrm{H}$ apparently resulted in an outbreak of staphylococcal sepsis. Dispersal from patient $G$ led only to nasal colonization of other patients.

Patient A carried and disseminated the same strain on three successive admissions whereas patient $C$ was not a carrier on his first admission but on readmission two years later carried and dispersed the type 6/53/75 referred to below. Patient D was a disperser on his first admission but not on his second four months later, although carrying the same types of staphylococci. The remaining dispersers were observed only once.

Although none of these patients had an infected lesion on admission to the wards six of them subsequently developed scme infection with the same staphylococcus as was carried nasally. Patient A 


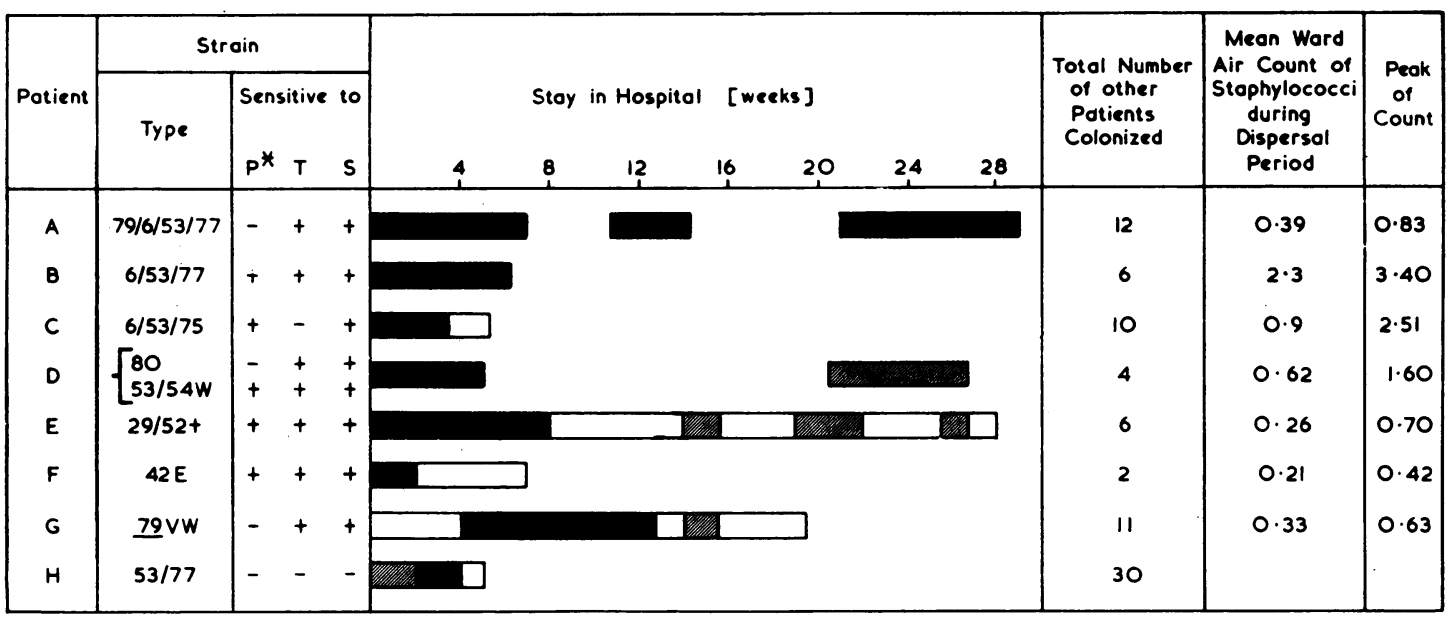

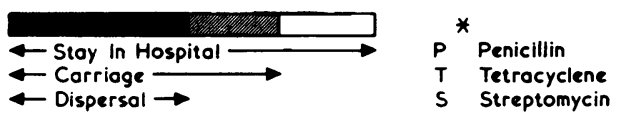

FIG. 2. Characteristics of dispersers in relation to their stay in hospital. Patient $H$ acquired his strain in another ward. As he was isolated in a cubicle the total number of patients infected with his strain and the air counts in the main ward are not directly related to his ability to disperse organisms.

had an infected colostomy in the sixth week of his first admission and a boil in the third week of his second admission. Patient B developed infection of an abdominal laparotomy wound during the fourth week of his stay in hospital and patient $C$ had an infected ulcer in the third week of his stay. Patient $\mathrm{E}$ had an infected sputum in the second week and patient $G$ a boil in the eighth week of his stay. Patient $\mathrm{H}$ had an infected sputum a few days after his admission to the ward. Only one of these infections, that of patient $G$, could be classed as severe. Patients D and F had no infections. Most of the infections developed some time after admission and it seems probable that they were the result of the large numbers of staphylococci found in the patients' environment rather than the cause of the dispersal.

\section{ENVIRONMENTAL STAPHYLOCOCCI}

RECOVERY OF STAPHYLOCOCCI FROM BLANKETS WhE the number of airborne staphylococci in the ward rose markedly above $0 \cdot 2$ per cu. $\mathrm{ft}$. an attempt was made to locate the source of the organisms by taking bedsweeps from the top blanket near the head of each bed. There was normally a delay of two to three days between the day on which the high air count occurred and the day on which the bedsweeps were taken.

Although the strain in the air was often recovered in small numbers from some or many of the beds in the ward, it was common to find one bed that was heavily contaminated and it is presumed that this bed was the source of the airborne organisms. From Table II it can be seen that over the 28 occasions on which bedsweeps were taken when a disperser was present, $76(12.4 \%)$ of the 615 beds examined yielded more than 20 colonies of staphylococci. These 76 beds were distributed amongst the 28 occasions, but there was a tendency to find more beds heavily contaminated when the disperser had been in the $N$ ward some time than soon after his arrival.

In the absence of a high air count more than $95 \%$ of the blankets yielded six or fewer colonies of staphylococci by the sweep plate method.

TABLE II

PERCENTAGE OF PATIENTS' BLANKETS YIELDING SPECIFIED NUMBER OF STAPHYLOCOCCI

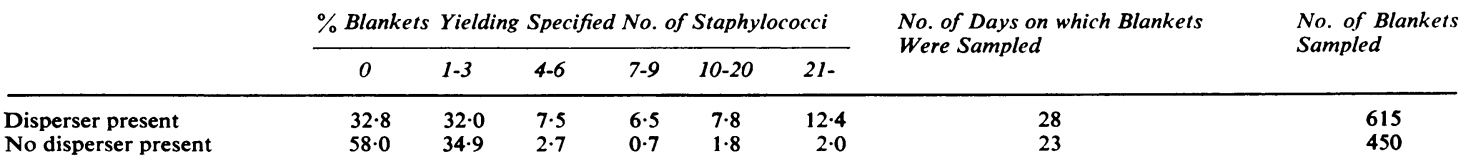


TABLE III

RECOVERY OF STAPHYLOCOCCI FROM BLANKETS

\begin{tabular}{llc} 
Patient & $\begin{array}{l}\text { No. of Staphylococcal Particles } \\
\text { Recovered per Square Inch }\end{array}$ & $\begin{array}{l}\text { Calculated No. } \\
\text { on Entire Blanket }\end{array}$ \\
\hline E, disperser & $56,76,77,78,83,100,127$, & 640,322 \\
G, disperser & $146,160,175$ & 148,500 \\
1, non-disperser & $\mathbf{6}, 7,40$ & 38,016 \\
2, non-disperser & 4,5 & 27,240 \\
3, non-disperser & 4,4 & 24,354 \\
4, non-disperser & 1,2 & 8,190 \\
The figures given above are the values of separate determinations \\
carried out on different areas of blanket.
\end{tabular}

Quantitative examination for staphylococci of blankets taken from the beds of two dispersers showed very large numbers of organisms, but examination of blankets from the beds of four non-dispersers yielded only small numbers of staphylococci (Table III).

RATE OF CONTAMINATION OF BEDDING Once bedclothes were put on the beds in the wards they became contaminated with staphylococci very quickly. Table IV shows the number and percentage of blankets from which staphylococci were recovered in relation to the length of time that the bed had been occupied by the patient.

The rapidity with which an active disperser can contaminate his bedding is shown by investigations on patient $\mathrm{C}$. This patient was given clean pyjamas, bedding, and curtains. After two hours, a sweep plate of the sheet on which he lay yielded more than 700 colonies of his staphylococcus and after five hours these organisms were recoverable from the curtains around his bed. The sheet became contaminated more rapidly than the blankets, suggesting that the organisms were derived from his body rather than from his nose.

Patient $\mathrm{C}$ was, by chance, observed from the moment of his arrival in the ward and he carried a rather distinctive type of staphylococcus (phage type $6 / 53 / 75$, resistant to tetracyclines but sensitive to penicillin). On the day of his admission, none of the beds in the ward carried type 6/53/75. During the
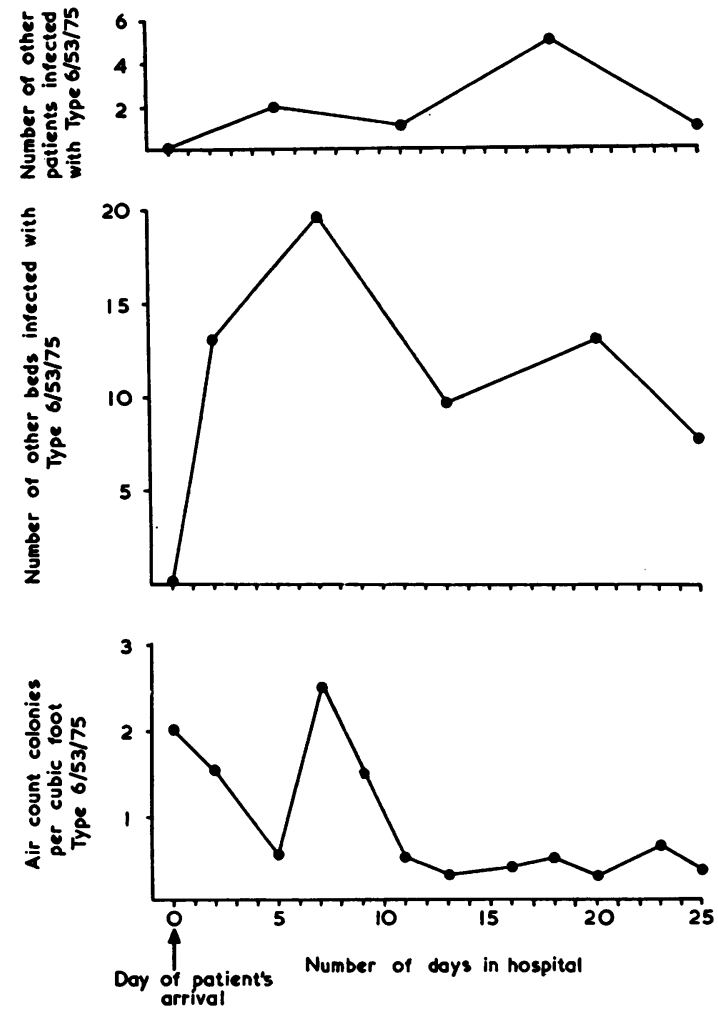

FIG. 3. Dispersal of staphylococci by patient $C$. On the day of this patient's arrival in the ward the first air sample yielded no colonies of his staphylococcus but the second sample yielded four colonies per cubic foot.

act of undressing he disseminated large numbers of organisms into the air and two days after his admission his type was recovered from 14 of the 22 beds. After one week, 20 of the 22 beds, 28 of the 30 curtains, 12 out of 12 window ledges, and three of the three sinks sampled were contaminated with this type of staphylococcus. The number of patients and beds from which this strain was subsequently isolated is shown in Figure 3.

\section{TABLE IV}

RECOVERY OF STAPHYLOCOCCI FROM BLANKETS ON BEDS IN WARD B

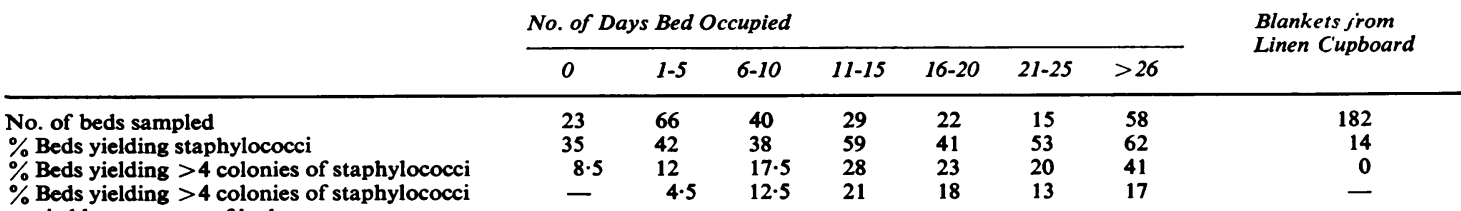
carried by occupant of bed

Clean blankets were put on the bed before the admission of all patients, after any patient had been in his bed for four weeks, and when indicated by soiling, etc. 
RELATION OF NUMBER OF AIRBORNE BACTERIA TO NUMBER OF CARRIERS When a disperser was present in the ward the number of staphylococci in the air bore little or no relation to the numbers of carriers of the strain, although the presence of large numbers of staphylococci in the air usually resulted in some other patients becoming carriers, as with the case illustrated in Figure 3.

For 11 episodes lasting more than six weeks when a strain was spreading amongst the patients but no disperser could be found, the number of carriers of the strain was plotted against the air count on the day of swabbing as a scatter diagram. Altogether there was little correlation between the number of carriers and the air count.

\section{DISPERSAL FROM FOMITES}

In an attempt to define the mechanism of dispersal rather more precisely, air sampling was carried out close to the beds of patients during bedmaking and wound dressing. The two groups of patients selected for these investigations were (a) six of the eight dispersers and 10 non-dispersers and (b) 23 patients suspected of having staphylococcal wound infection, staphylococci being isolated from the wounds of 11 of these patients.

Investigation of a further 10 patients with staphylococcal pneumonia showed that only two of them were disseminating organisms and then in very small numbers.

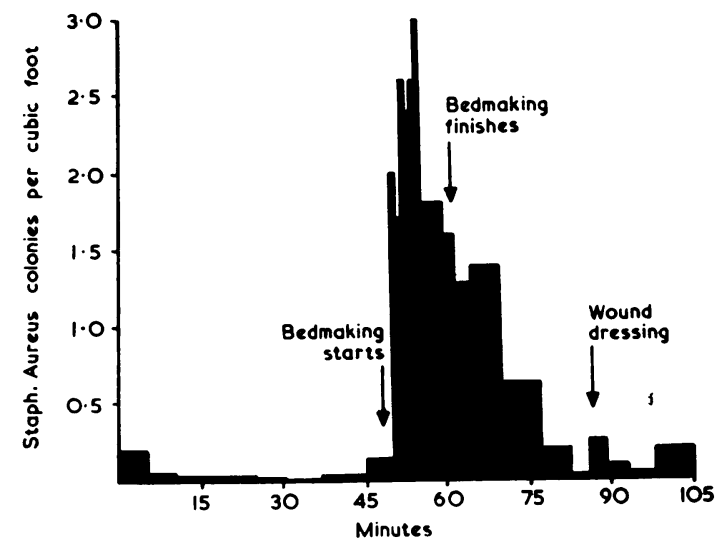

FIG. 4. Dispersal of staphylococci during bedmaking.

DISPERSAL DURING BEDMAKING Bedmaking was studied on 24 occasions. On 19 of these occasions there was an increase in the number of airborne staphylococci and on the remaining five occasions an increase in the total bacterial flora only. The recognized dispersers liberated more staphylococci than the non-dispersers (Table V). An example of the timing of the dispersal in relation to bedmaking is given in Figure 4. It can be seen that few staphylococci were liberated until the bedclothes were disturbed even though a blood sample was taken from the patient in the period before bedmaking.

TABLE V

INCREASE IN NUMBERS OF AIRBORNE STAPHYLOCOCCI DURING BEDMAKING

\begin{tabular}{|c|c|c|c|c|}
\hline \multirow[t]{2}{*}{ Patient } & \multirow{2}{*}{$\begin{array}{l}\text { Staphylococci } \\
\text { in Nose }\end{array}$} & \multirow{2}{*}{$\begin{array}{l}\text { Staphylococci } \\
\text { in Wound }\end{array}$} & \multicolumn{2}{|c|}{ No. of Colonies of Staphylococci in Air } \\
\hline & & & Before Bedmaking & Peak of Count \\
\hline \multicolumn{5}{|c|}{ Dispersers } \\
\hline A & + & -- & 0.08 & $2 \cdot 20$ \\
\hline A & $\perp$ & $\div$ & 0.64 & $2 \cdot 10$ \\
\hline A & 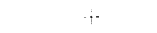 & + & $0 \cdot 10$ & $1 \cdot 60$ \\
\hline A & + & - & 1.00 & $1 \cdot 30$ \\
\hline B & $T$ & - & 0.40 & $9 \cdot 50$ \\
\hline D & + & - & $9 \cdot 00$ & $36 \cdot 00$ \\
\hline D & + & + & $0 \cdot 10$ & $5 \cdot 40$ \\
\hline D & + & - & 0.50 & $4 \cdot 50$ \\
\hline D & 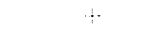 & $\therefore$ & $0 \cdot 20$ & $3 \cdot 10$ \\
\hline D & + & - & $0 \cdot 06$ & 3.00 \\
\hline $\mathbf{E}$ & + & $\therefore$ & $12 \cdot 00$ & 53.00 \\
\hline E & + & + & $0 \cdot 10$ & $20 \cdot 60$ \\
\hline $\mathbf{F}$ & + &.+ & 0.09 & $2 \cdot 40$ \\
\hline $\mathbf{G}$ & + & + & $0 \cdot 50$ & $7 \cdot 90$ \\
\hline \multicolumn{5}{|c|}{ Non-dispersers } \\
\hline $\mathbf{a}$ & - & + & 1.00 & $2 \cdot 40$ \\
\hline b & + & + & $0 \cdot 10$ & $1 \cdot 70$ \\
\hline c & - & - & $0 \cdot 10$ & 0.90 \\
\hline d & + & - & 0.09 & 0.80 \\
\hline e & + & + & $0 \cdot 10$ & 0.40 \\
\hline f & - & - & $0 \cdot 19$ & $0 \cdot 38$ \\
\hline g & - & - & 0.20 & $0 \cdot 13$ \\
\hline $\mathrm{h}$ & - & + & 0.40 & 0.09 \\
\hline $\mathrm{i}$ & + & $\div$ & 0.11 & 0.06 \\
\hline $\mathrm{j}$ & + & - & 0.05 & 0.00 \\
\hline
\end{tabular}

No. of Colonies of Staphylococci in Air

Before Bedmaking Peak of Count 
One of the investigations was carried out in an exhaust-ventilated cubicle of about $1,000 \mathrm{cu}$. ft. capacity. A peak count of 53 staphylococcal particles per cu. ft. was obtained, suggesting that rather more than 50,000 staphylococcal particles must have been liberated during the process of bedmaking.

DISPERSAL FROM CURTAINS Disturbance of bedside curtains was observed on 41 occasions. On 32 of these occasions there was an increase in the total airborne flora and on 26 occasions there was an increase in the staphylococcal flora. On 17 of these 26 occasions some or all of the staphylococci recovered were of the same phage type as carried by a patient in an adjoining bed.

DISPERSAL DURING WOUND DRESSING PROCEDURES When investigating the spread of staphylococci from the wound itself, it is necessary to eliminate as far as possible all other sources of organisms for, as shown above, disturbance of the bedding can result in dispersal. In our experiments the bedding was therefore changed and the patient put in clean pyjamas before the dressing was done. Where these experiments were carried out in the main ward, care was taken not to disturb the curtains after the start of the sampling. Many of the experiments were, however, performed in the isolation rooms. There was, of course, still the possibility that the wound dressing was contaminated on the outside with organisms from the nose or other carrier site, but this could hardly be avoided.

Wound dressing procedures were observed on 25 occasions involving 23 patients. On 12 of these occasions the wound was found to be infected with staphylococci (Table VI). An increase in the number of staphylococci in the air was seen during the dressing of six of the 12 infected wounds and two of the 13 uninfected wounds.

PERSISTENCE OF ORGANISMS IN THE WARD In experiments with five blankets removed from the beds of patients and kept in the laboratory, staphylococci were recovered for periods up to 203 days. However, staphylococci seem to disappear from the air of the ward very rapidly after the last-known carrier is discharged. Thus for 20 episodes when a strain was spreading amongst the patients, a search was made amongst the strains isolated from the air of the ward in the week after the discharge of the last-known

\section{TABLE VI}

DISPERSAL OF STAPHYLOCOCCI DURING DRESSING OF INFECTED WOUNDS

\begin{tabular}{|c|c|c|c|c|c|}
\hline \multirow[t]{2}{*}{ Patient } & \multicolumn{2}{|l|}{ State of Wound } & \multirow{2}{*}{$\begin{array}{l}\text { Whether Patient is Nasal } \\
\text { Carrier of Wound } \\
\text { Staphylococcus }\end{array}$} & \multicolumn{2}{|c|}{ No. of Colonies of Staphylococci in A } \\
\hline & Bacteriological & Clinical & & Before Dressing & Peak of Dressing \\
\hline $\mathbf{F}$ & Staphylococci & Healthy & + & $0 \cdot 10$ & $2 \cdot 40$ \\
\hline 2 & Staphylococci & Healthy & - & 0.02 & 0.40 \\
\hline $\mathbf{F}$ & Staphylococci & Healthy & + & $0 \cdot 13$ & 0.80 \\
\hline 4 & Staphylococci & Slight infection & + & 0.03 & $0 \cdot 16$ \\
\hline 5 & Staphylococci & Healthy & - & 1.00 & $2 \cdot 40$ \\
\hline 6 & Staphylococci & Healthy & + & $0 \cdot 30$ & 0.80 \\
\hline 7 & Staphylococci & Healthy & $\underline{-}$ & 0.08 & 0.13 \\
\hline $\mathbf{A}$ & Staphylococci & Slight infection & + & $0 \cdot 10$ & 0.12 \\
\hline $\mathbf{E}$ & Staphylococci & Healthy & + & 1.00 & $1 \cdot 10$ \\
\hline $\overrightarrow{\mathbf{D}}$ & Staphylococci & Slight infection & + & 0.20 & 0.20 \\
\hline 11 & Staphylococci & Slight infection & + & 0.60 & 0.60 \\
\hline $\mathbf{A}$ & Staphylococci & Slight infection & + & 0.15 & 0.15 \\
\hline 13 & No staphylococci & Healthy & Nasal carrier & $0 \cdot 10$ & 0.24 \\
\hline 14 & No staphylococci & Healthy & Nasal carrier & 0.03 & 0.22 \\
\hline $15-25$ & No staphylococci & Healthy & Some nasal carriers & & ise in count \\
\hline
\end{tabular}

Slight wound infection is used to indicate the appearance of some pus and inflammation at the wound edges.

TABLE VII

PERSISTENCE OF STAPHYLOCOCCI IN AIR OF WARDS AFTER DISCHARGE OF LAST-KNOWN CARRIERS OF STRAINS SPREAD AMONGST PATIENTS

\begin{tabular}{|c|c|c|c|c|c|}
\hline Phage Type & Strains Typed & $\begin{array}{l}\text { No. Strains of } \\
\text { Index Type Found }\end{array}$ & $\begin{array}{l}\text { Count per cu.ft } \\
\text { of Index Type }\end{array}$ & $\begin{array}{l}\text { Count per cu. ft. } \\
\text { on Last Day of } \\
\text { Carrier's Admission }\end{array}$ & $\begin{array}{l}\text { No. Days Since } \\
\text { Last Carrier } \\
\text { Present }\end{array}$ \\
\hline $\begin{array}{l}52 \mathrm{~A} / 79 \\
52 / 52 \mathrm{~A} / 80 \\
52 \mathrm{~A} / 79 \\
52 / 52 \mathrm{~A} / 79 / 80 / 7 / 42 \mathrm{E} \\
79 \\
\text { Various strains taken from } 15 \text { other episodes }\end{array}$ & $\begin{array}{r}16 \\
17 \\
29 \\
11 \\
13 \\
259\end{array}$ & $\begin{array}{l}1 \\
1 \\
1 \\
1 \\
1\end{array}$ & $\begin{array}{r}0.01 \\
0.01 \\
0.01 \\
0.01 \\
0.01 \\
<0.01\end{array}$ & $\begin{array}{c}0.05 \\
0.03 \\
0.02 \\
0.10 \\
0.05 \\
0.02-0 \cdot 17\end{array}$ & $\begin{array}{c}1 \\
2 \\
3 \\
4 \\
5 \\
1-7\end{array}$ \\
\hline
\end{tabular}


carrier. In only five of these cases were such staphylococci recovered (Table VII), four from ward B and one from ward C. A total of 259 staphylococci was examined from the air samples taken after the end of the remaining 15 episodes without any strains of the appropriate type being recovered.

\section{DISCUSSION}

During this study, which lasted nearly four years, 3,675 patients were admitted to the wards and 1,488 of these patients carried staphylococci in the nose on admission but we detected only six patients who had the ability to contaminate their environment heavily with staphylococci. About $18 \%$ (662) of the patients acquired a staphylococcus in the nose during their stay in hospital but only two of these had the ability to disperse this staphylococcus to any marked extent.

Although 81 other patients became colonized with the same types of staphylococci as carried by the eight dispersers, none of them were observed to become dispersers themselves. Hence it seems likely that the ability to disperse is a property of the patient rather than of the staphylococcus. There seems to have been no common factor such as age, disease, or type of staphylococcus carried in this series of patients.

Four factors have been recognized in other work on the dispersal of organisms. Eichenwald, Kotsevalov, and Fasso (1960) found that their 'cloud babies' apparently disseminated organisms from the respiratory tract and that the ability to disseminate staphylococci was sometimes associated with adenovirus infection, but this factor was not investigated in this study. White (1961) showed that patients from whom large numbers of staphylococci could be recovered by nasal swabbing carried more staphylococci on the skin and disseminated more staphylococci from their bedding than non-carriers or carriers with only slight nasal growth. We have no information as to the heaviness of nasal carriage of staphylococci amongst the patients in this survey but when there was no disperser present in the ward staphylococci were recovered from the beds of $59 \%$ of the nasal carriers and from $36 \%$ of the noncarriers. The same phage type as was carried in the nose of the patient was isolated from $39 \%$ of the beds. Hare and Cooke (1961) found that patients with eczema or mycosis fungoids carried many staphylococci on the skin and contaminated their $\stackrel{0}{\circ}$ bedding with staphylococci. Patients with lesions which could be covered, such as wound infection, boils, etc., liberated few staphylococci unless there was a profuse discharge from the lesion. In the investigations reported above, only one of the patients in had a severely infected lesion and this developed four weeks after he had begun dispersing the organism. Hare and his colleagues have emphasized the importance of perineal carriage of staphylococci in relation to dispersal. It was not possible, however, in our study to carry out routine skin swabbing but perineal swabs taken from three of the dispersers (A, B, and D) all yielded staphylococci of the same type as carried in the nose. Skin swabbing was not carried out on the other five dispersers.

Although the strains disseminated by the dispersers were recovered from the noses of the other patients and the lesions on the dispersers themselves, only one strain caused any sepsis amongst other patients in the ward. This was the strain with which patient $\mathbf{H}$ was admitted to the ward under investigation from another ward. Thus it appears that the dispersal of staphylococci, even in enormous numbers, does not lead to cross-infection unless the strain itself has epidemic propensities; this same strain was able to spread through another ward without any dispersers being apparent.

The studies reported in this paper constituted part of the $\overline{\bar{O}}$ larger investigation referred to above (Williams et al., 1962) and arose as a result of the discussions held by the workers involved in that investigation, to whom I am extremely grateful. I should like to record my indebtedness to the Treasurer and Governors of St. Bartholomew's Hospital for permission to work in the wards.

\section{REFERENCES}

Barber, Mary, and Kuper, S. W. A. (1951). J. Path. Bact., 63, 65. Eichenwald, H. F., Kotsevalov, O., and Fasso, L. A. (1960). Amer. J. Dis. Child., 100, 161.

Hare, R., and Cooke, E. M. (1961). Brit. med. J., 2, 333.

Shooter, R. A., Smith, M. A., Griffiths, J. D., Brown, Mary E. A., Williams, R. E. O., Rippon, Joan E., and Jevons, M. Patricia O (1958). Ibid. 1, 607

White, A. (1961). J. Lab. clin. Med., 58, 273.

Williams, R. E. O., Blowers, R., Garrod, L. P., and Shooter, R. A. N (1960). Hospital Infection: Lloyd-Luke, London. Noble, W. C., Jevons, M. Patricia, Lidwell, O. M., Shooter, O R. A., White, R. G., Thom, B. T., and Taylor, G. W. (1962). Brit, med. $J, 2,275$. 